\title{
SEMUA SUBGRUP SIKLIK DARI GRUP $\left(\mathbf{Z}_{n},+\right)$ \\ Indra Bayu Muktyas', Samsul Arifin² \\ 1,2Program Studi Pendidikan Matematika, STKIP Surya \\ email: indrabayu.muktyas@stkipsurya.ac.id
}

\begin{abstract}
ABSTRAK
Grup $\left(\mathbf{Z}_{n},+\right)$ adalah grup himpunan bilangan bulat modulo $\mathrm{n}$ terhadap operasi penjumlahan modulo $\mathrm{n}$. Subgrup siklik adalah subgrup yang dibangun oleh satu buah elemen suatu grup. Pada grup $\left(\mathbf{Z}_{n},+\right)$, semua subgrup siklik di dalamnya dapat ditentukan melalui pembangun yang merupakan faktor dari n. Dalam tulisan ini akan ditentukan semua subgrup siklik di grup $\left(\mathbf{Z}_{n},+\right)$ dengan menggunakan bantuan pemrograman Python.

Kata Kunci: Grup $\left(\mathbf{Z}_{n},+\right)$, Subgrup Siklik, Python.
\end{abstract}

Dikirim: 13 Agustus 2018; Diterima: 17 September 2018; Dipublikasikan: 29 September 2018

Cara sitasi: Muktyas, I. B., dan Arifin, S. 2018. Semua Subgrup Siklik dari Grup $\left(\mathbf{Z}_{n},+\right)$. Jurnal Teorema: Teori dan Riset Matematika. Vol 3 No 2, Hal 177-186, September 2018. 


\section{PENDAHULUAN}

Suatu grup adalah himpunan tak kosong $G$ yang dilengkapi dengan operasi biner *, sedemikian hingga berlaku tertutup, asosiatif, terdapat elemen identitas dan setiap elemen memiliki invers. Jika suatu grup memiliki sifat $a * b=b^{*} a$, untuk setiap elemen $a$ dan $b$, maka dikatakan bahwa grup tersebut komutatif. Sifat-sifat dasar mengenai grup dibahas oleh Fraleigh (2000), Herstein (1996) dan Isaacs (1994). Grup Siklik adalah grup di mana setiap elemennya dapat ditulis sebagai perpangkatan dari setiap unsur tetap pada grup tersebut. Karakteristik dari grup siklik dibahas oleh Rotman (2003), Gallian (2017) dan Malik (1997).

Subgrup adalah subhimpunan $\mathrm{H}$ di dalam grup $\mathrm{G}$ yang juga merupakan grup dengan operasi biner yang sama di $G$. Untuk suatu a elemen grup $G$, dapat dibentuk subhimpunan $S$ berisi semua elemen $G$ yang merupakan hasil perpangkatan dari elemen a. Subhimpunan $S$ tersebut membentuk subgrup di $G$, dan disebut subgrup siklik yang dibangun/direntang oleh a. Ingat bahwa setiap grup siklik adalah grup komutatif dan subgrup dari suatu grup siklik juga siklik.

Himpunan semua bilangan bulat modulo $\mathrm{n}$, dinotasikan dengan $\mathbf{Z}_{n}$, adalah suatu grup terhadap operasi penjumlahan modulo. Grup $\mathbb{Z}_{n}$ ini menjadi salah satu contoh yang sangat penting dalam mempelajari teori grup. Grup $\left(\mathbf{Z}_{n},+\right)$ dikonstruksi dengan memanfaatkan algoritma pembagian pada himpunan semua bilangan bulat $\mathbf{Z}$. Proses pembentukan $\mathbf{Z}_{n}$ dibahas oleh Dummit (2004).

Pengaplikasian dari grup $\left(\mathbb{Z}_{n},+\right)$ dapat dilakukan dengan bantuan pemrograman komputer berbahasa Python. Python adalah salah satu bahasa pemrograman yang mudah untuk dipelajari. Python juga dapat berjalan di berbagai sistem operasi, seperti Windows yang dibahas pada Python (2018), Linux, Mac OS, Android yang dibahas pada QPython (2018), dan lain lain. Dalam tulisan ini akan dikaji penentuan semua subgrup siklik dari grup $\left(\mathbf{Z}_{n},+\right)$ dengan menggunakan bantuan pemrograman Python.

\section{METODE PENELITIAN}

Secara umum metode penelitian yang digunakan dalam penelitian ini adalah metode eksplorasi dan adaptasi dari hasil-hasil yang sudah ada, yang dicermati dari studi literatur. Berikut ini adalah gambaran tahapan dari rencana kerja yang ditempuh dalam penelitian tentang penentuan semua subgrup siklik dari grup $\left(\mathbf{Z}_{n},+\right)$ dengan menggunakan Python. Untuk mencapai sasaran penelitian yang ingin dicapai, penelitian dibagi menjadi tiga tahapan, yaitu mengkaji tentang konsep grup dan subgrup siklik, menentukan langkah-langkah dalam menentukan semua subgrup siklik dari grup $\left(\mathbf{Z}_{n},+\right)$, dan membuat programnya menggunakan Python.

\section{HASIL DAN PEMBAHASAN \\ PENGERTIAN GRUP $\left(\mathbf{Z}_{n},+\right)$}

Di sesi ini akan dikaji mengenai konstruksi dari grup $\left(\mathbf{Z}_{n},+\right)$. Dalam tulisan ini diasumsikan bahwa semua grup bersifat komutatif. Berikut diberikan pengertian dari grup.

Dikirim: 13 Agustus 2018; Diterima: 17 September 2018; Dipublikasikan: 29 September 2018

Cara sitasi: Muktyas, I. B., dan Arifin, S. 2018. Semua Subgrup Siklik dari Grup $\left(\mathbf{Z}_{n},+\right)$. Jurnal Teorema: Teori dan Riset Matematika. Vol 3 No 2, Hal 177-186, September 2018. 


\section{Definisi 2.1. Fraleigh [1]}

Diberikan himpunan tak kosong $\mathrm{G}$ yang dilengkapi dengan operasi “*”. Himpunan $\mathrm{G}$ disebut grup terhadap operasi “* "jika memenuhi empat aksioma berikut ini:

1. $(\forall a, b \in G) a * b \in G$

2. $(\forall a, b, c \in G)(a * b) * c=a *(b * c)$

3. $(\exists e \in G)(\forall a \in G) a * e=e * a=a$

4. $(\forall a \in G)\left(\exists a^{-1} \in G\right) a * a^{-1}=a^{-1} * a=e$

Dalam Gallian (2017), telah dibuktikan bahwa elemen identitas dan elemen invers dari suatu grup adalah tunggal, berlaku sifat kanselasi dan berlaku sifat Socks-Shoes. Selanjutnya diberikan pengertian mengenai salah satu contoh grup, yaitu $\left(\mathbb{Z}_{n},+\right)$. Grup tersebut dibentuk dengan memanfaatkan algoritma pembagian pada himpunan semua bilangan bulat $\mathbb{Z}$.

Ingat bahwa suatu relasi " " disebut relasi ekivalensi jika bersifat reflektif, simetris, dan transitif. Diberikan suatu $a \in \mathbf{Z}$ dan bilangan bulat positif $n \in \mathbb{Z}^{+}$. Berdasarkan algoritma pembagian pada bilangan bulat, terdapat dengan tunggal $k, l \in \mathbb{Z}$ sedemikian hingga berlaku $a=k n+l$ dengan $0 \leq l \leq n-1$. Bilangan bulat $k$ disebut hasil bagi (quotient) dan bilangan bulat $/$ disebut sisa (residu). Sisa pembagian / ditulis $l=a \bmod n$. Selanjutnya, disajikan konsep kongruensi pada bilangan bulat sebagai berikut. Misalkan diberikan bilangan bulat $a, b \in \mathbf{Z}$ dan bilangan bulat positif $n \in \mathbf{Z}$. Bilangan bulat a disebut kongruen $b$ modulo $n$ jika berlaku $n \mid a-b$, ditulis dengan $a \equiv b(\bmod n)$. Mudah ditunjukkan bahwa kongruensi modulo $n$ adalah relasi ekivalensi. Oleh karena itu, himpunan $\mathbf{Z}$ terbagi menjadi kelas-kelas himpunan yang tidak beririsan. Untuk suatu elemen $a \in \mathbf{Z}$, berlaku $\bar{a}=\{x \in \mathbf{Z} \mid x \equiv a(\bmod n)\}$, yaitu kelas himpunan yang memuat a. Secara umum, untuk setiap $n \in \mathbf{Z}^{\star}$, terdapat $n$ partisi yang tidak beririsan pada himpunan $\mathbf{Z}$, yaitu $\overline{0}, \overline{1}, \overline{2}, \ldots$, dan $\overline{n-1}$.

Dibentuk himpunan $\mathbf{Z}_{n}$, yaitu himpunan yang berisi koleksi semua kelas yang diperoleh dari relasi ekivalensi kongruen modulo $n$, ditulis $\mathbf{Z}_{n}=\{\overline{0}, \overline{1}, \overline{2}, \ldots, \overline{n-1}\}$. Pada himpunan $\mathbf{Z}_{n}$ didefinisikan operasi penjumlahan "+", yaitu untuk setiap $\bar{a}, \bar{b} \in \mathbf{Z}_{n}$ didefinisikan $\bar{a}+\bar{b}:=\overline{a+b}$. Dapat ditunjukkan bahwa $\left(\mathbf{Z}_{n},+\right)$ merupakan grup komutatif komutatif dengan elemen identitasnya adalah $\overline{0} \in \mathbf{Z}_{n}$.

\section{PENGERTIAN SUBGRUP SIKLIK}

Dalam sesi ini akan dikaji mengenai subgrup siklik. Berikut adalah definisi dari grup siklik dan pembangun dari suatu grup.

\section{Definisi 3.1. Adkins [6].}

Suatu grup $(G, *)$ disebut grup siklik jika terdapat $g \in G$ sedemikian hingga untuk setiap $a \in G$ dapat dinyatakan sebagai $a=g^{n}$, untuk suatu $n \in \mathbf{Z}$. Elemen $g \in G$ tersebut disebut dengan generator atau elemen pembangun grup $(G, *)$, dinotasikan dengan $G=\langle g\rangle$.

Dikirim: 13 Agustus 2018; Diterima: 17 September 2018; Dipublikasikan: 29 September 2018

Cara sitasi: Muktyas, I. B., dan Arifin, S. 2018. Semua Subgrup Siklik dari Grup $\left(\mathbf{Z}_{n},+\right)$. Jurnal Teorema: Teori dan Riset Matematika. Vol 3 No 2, Hal 177-186, September 2018. 
Dari definisi grup siklik di atas, jelas bahwa $G=\langle g\rangle=\left\{g^{n} \mid n \in \mathbf{Z}\right\}$ untuk suatu pembangun $g \in G$. Perhatikan contoh berikut. Grup $\left(\mathbf{Z}_{72},+\right)$ merupakan grup siklik yang dibangun oleh $1 \in \mathbf{Z}_{72}$, yaitu $\mathbf{Z}_{72}=\langle 1\rangle$. Di lain pihak, grup $\left(\mathbf{Z}_{72},+\right)$ ternyata juga dibangun oleh $11 \in \mathbf{Z}_{72}$, yaitu $\mathbf{Z}_{72}=\langle 11\rangle$. Mudah dilihat bahwa grup $\left(\mathbf{Z}_{72},+\right)$ adalah grup komutatif. Hal ini senada dengan sifat bahwa setiap grup siklik adalah grup komutatif (lihat[1]).

Misalkan diberikan grup $(G, *)$ dan himpunan bagian tidak kosong $H \subseteq G$. Ingat bahwa himpunan $H$ dikatakan subgrup dari $(G, *)$ jika $H$ juga merupakan grup terhadap operasi biner "* " yang sama pada grup $G$, dinotasikan dengan $H \leq G$ ( Herstein (1996)). Rotman (2003) menjelaskan bahwa suatu subhimpunan dari suatu grup dapat diuji apakah merupakan subgrup atau bukan, yaitu misalkan diberikan grup $(G, *)$ dan $H$ suatu subhimpunan tidak kosong dari $G$, maka $H \leq G$ jika berlaku $(\forall a, b \in H) a * b^{-1} \in H$. Selanjutnya akan dibuktikan bahwa untuk suatu elemen $g \in G$, dapat dibentuk subhimpunan dengan pembangun $g \in G$ dan membentuk subgrup di $(G, *)$.

\section{Teorema 3.2. Dummit [2].}

Diberikan grup $G$ dan $g \in G$, maka $\langle g\rangle=\left\{g^{n} \mid n \in \square\right\}$ merupakan subgrup dari G. Selanjutnya, $\langle g\rangle$ disebut dengan subgrup siklik dari $G$ dengan pembangun $g$.

Bukti: Jelas bahwa $\langle g\rangle \subseteq G$ dan $\langle g\rangle$ tidak kosong, sebab $g^{0}=e \in\langle g\rangle$. Selanjutnya diambil sebarang $a, b \in\langle g\rangle$, maka $a=g^{m}$ dan $b=g^{n}$, untuk suatu $m, n \in \square$, sehingga $m-n \in \square$. Selanjutnya, perhatikan bahwa $a b^{-1}=g^{m}\left(g^{n}\right)^{-1}=g^{m} g^{-n}=g^{m-n} \in\langle g\rangle$. Dengan demikian, terbukti bahwa $\langle g\rangle$ subgrup dari $G$.

Ingat bahwa order suatu subgrup adalah banyaknya elemen dari subgrup tersebut. Perhatikan contoh berikut.

\section{Contoh 3.3.}

Diberikan grup $\mathbf{Z}_{106}=\{0,1,2, \ldots, 105\}$ terhadap operasi penjumlahan modulo 106. Himpunan $S=\{0,2, \ldots, 104\}$ adalah subgrup dari grup $\left(\mathbf{Z}_{106},+\right)$ yang dibangun oleh $2 \in \mathbf{Z}_{106}$ dengan order 53.

Misalkan diberikan sebarang $n, k \in \mathbf{Z}^{+}$. Perhatikan bahwa $\operatorname{FPB}(n, k)=1$ bermakna bahwa tidak ada faktor persekutuan lain dari $n$ dan $k$ selain 1. Berikut adalah lemma yang mengatakan bahwa pembangun dari grup $\left(\mathbf{Z}_{n},+\right)$ adalah bilangan $k$ sedemikian hingga berlaku $\operatorname{FPB}(n, k)=1$, serta subgrup-subgrup di grup $\left(\mathbf{Z}_{n},+\right)$ adalah subhimpunan yang dibangun oleh faktor-faktor dari $n$.

Dikirim: 13 Agustus 2018; Diterima: 17 September 2018; Dipublikasikan: 29 September 2018

Cara sitasi: Muktyas, I. B., dan Arifin, S. 2018. Semua Subgrup Siklik dari Grup $\left(\mathbf{Z}_{n},+\right)$. Jurnal Teorema: Teori dan Riset Matematika. Vol 3 No 2, Hal 177-186, September 2018. 


\section{Lemma 3.4. Gallian [7].}

a) Suatu $k \in \mathbf{Z}_{n}$ adalah pembangun dari $\mathbf{Z}_{n}$ jhj $\operatorname{FPB}(n, k)=1$.

b) Di grup $\left(\mathbf{Z}_{n},+\right),\left(\forall k \in \mathbf{Z}^{+}\right)$pembagi dari $n$, himpunan $\left\langle\frac{n}{k}\right\rangle$ adalah subgrup tunggal di $\mathbf{Z}_{n}$ dengan order $k$. Lebih lanjut, hanya $\left\langle\frac{n}{k}\right\rangle$ subgrup-subgrup di $\mathbf{Z}_{n}$.

Lemma tersebut menjamin bahwa semua subgrup siklik di grup $\left(\mathbf{Z}_{n},+\right)$ adalah subhimpunan yang dibangun oleh semua faktor dari $n$. Hal ini yang akan menjadi dasar dari penentuan semua subgrup siklik di pemrograman menggunakan Python. Perhatikan contoh berikut.

\section{Contoh 3.5.}

Misalkan diberikan grup $\mathbf{Z}_{70}=\{0,1,2, \ldots, 69\}$. Ingat bahwa faktor dari $n$ adalah $\{1,2,5,7,10,14,35$, 70\}, sehingga diperoleh subgrup-subgrup di grup $\left(\mathbf{Z}_{70},+\right)$ adalah:

$\langle 1\rangle=\{0,1, \ldots, 69\}$ order 70

$\langle 2\rangle=\{0,2, \ldots, 68\}$ order 35

$\langle 5\rangle=\{0,5, \ldots, 65\}$ order 14

$\langle 7\rangle=\{0,7, \ldots, 63\}$ order 10

$\langle 10\rangle=\{0,10, \ldots, 60\}$ order 7

$\langle 14\rangle=\{0,14, \ldots, 56\}$ order 5

$\langle 35\rangle=\{0,35\}$ order 70

$\langle 70\rangle=\{0\}$ order 70

Elemen pembangun suatu subgrup siklik tidak tunggal. Perhatikan kembali contoh berikut. Misalkan diberikan grup $\left(\mathbf{Z}_{100},+\right)$. Subgrup siklik dengan pembangun $10 \in \mathbf{Z}_{100}$ adalah $\langle 10\rangle=\left\{10^{n} \mid n \in \mathbf{Z}\right\}=\{0,10,20, \ldots, 90\}$. Subgrup siklik dengan pembangun $11 \in \mathbf{Z}_{100}$ adalah sebagai berikut, $\langle 11\rangle=\left\{11^{n} \mid n \in \mathbf{Z}\right\}=\left\{11^{0}=0,11^{1}=11,11^{2}=22,11^{3}=33, \ldots\right\}=\{0,1,2, \ldots, 99\}=\mathbf{Z}_{100}$. Dapat dilihat bahwa $\langle 11\rangle=\mathbf{Z}_{100}$, yaitu $11 \in \mathbf{Z}_{100}$ merupakan elemen pembangun dari grup siklik $\left(\mathbf{Z}_{100},+\right)$ . Di lain pihak grup $\left(\mathbf{Z}_{100},+\right)$ juga dibangun oleh 1 , yaitu $\mathbf{Z}_{100}=\langle 1\rangle$.

\section{PEMBAHASAN HASIL}

Dalam sesi ini akan dikaji pemrograman dalam menentukan semua subgrup siklik dari grup $\left(\mathbf{Z}_{n},+\right)$ dengan menggunakan Python 2.7.14, yang merupakan hasil utama dari tulisan ini. Hal-hal yang menjadi dasar dalam pembuatan program adalah Lemma 3.4. di atas. Berikut adalah tampilan pemrograman yang digunakan dalam tulisan ini.

Dikirim: 13 Agustus 2018; Diterima: 17 September 2018; Dipublikasikan: 29 September 2018

Cara sitasi: Muktyas, I. B., dan Arifin, S. 2018. Semua Subgrup Siklik dari Grup $\left(\mathbf{Z}_{n},+\right)$. Jurnal Teorema: Teori dan Riset Matematika. Vol 3 No 2, Hal 177-186, September 2018. 


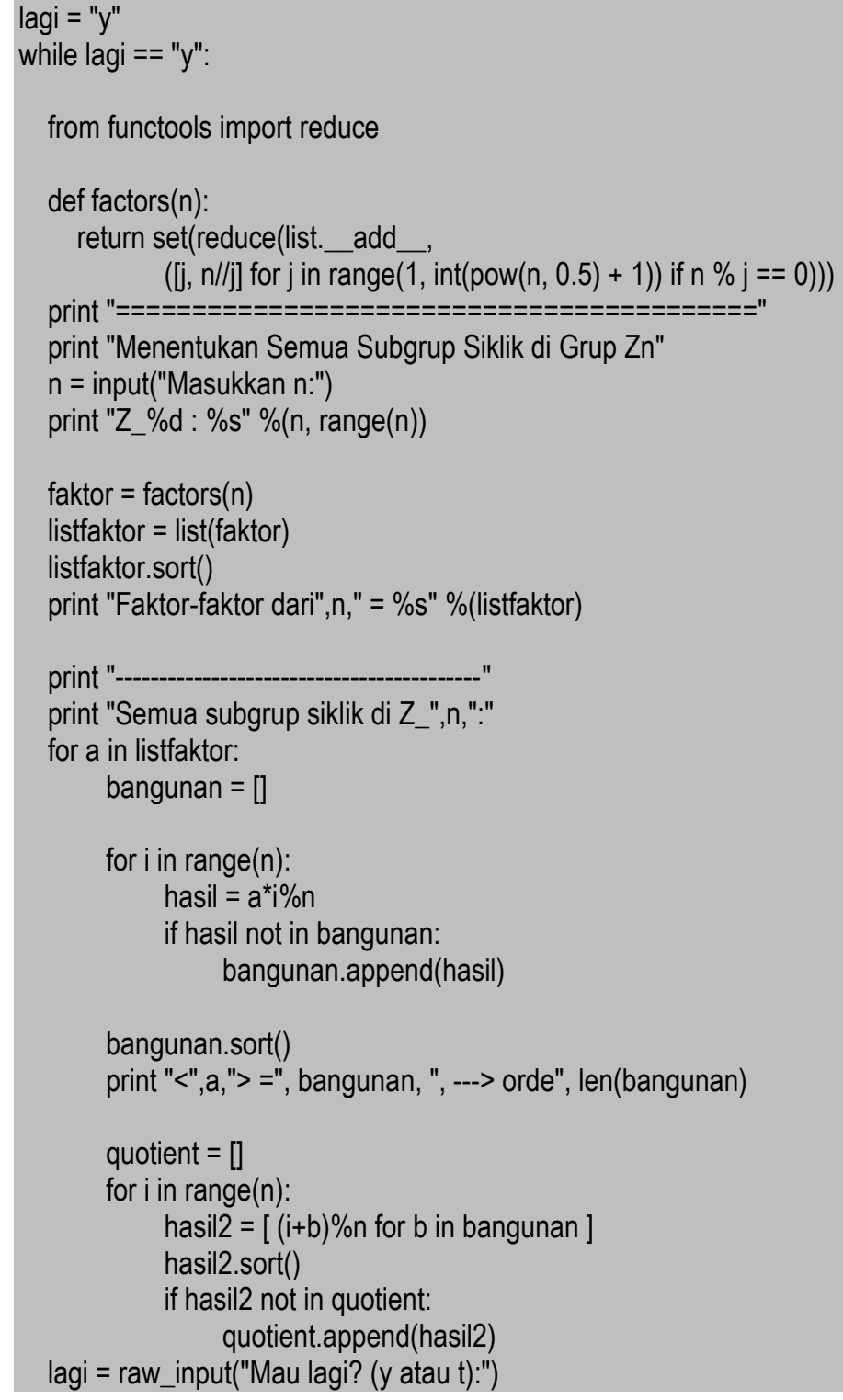

Berikut adalah tampilan program menggunakan Python dan contoh output dari program di atas, yaitu untuk grup $\left(\mathbf{Z}_{72},+\right)$ dan $\left(\mathbf{Z}_{108},+\right)$ untuk versi OS Windows.

Dikirim: 13 Agustus 2018; Diterima: 17 September 2018; Dipublikasikan: 29 September 2018

Cara sitasi: Muktyas, I. B., dan Arifin, S. 2018. Semua Subgrup Siklik dari Grup $\left(\mathbf{Z}_{n},+\right)$. Jurnal Teorema: Teori dan Riset Matematika. Vol 3 No 2, Hal 177-186, September 2018. 


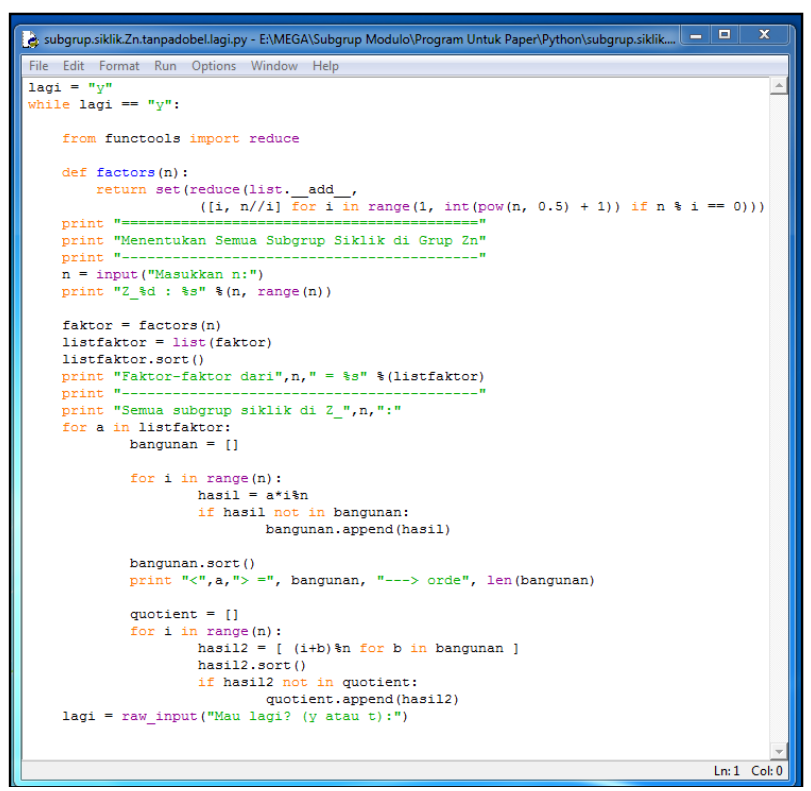

Berikut adalah tampilan program menggunakan Python dan contoh output dari program di atas, yaitu untuk grup $\left(\mathbf{Z}_{72},+\right)$ dan $\left(\mathbf{Z}_{108},+\right)$ untuk versi OS Windows. Tampilan keluaran berikut akan menutup sesi ini.

\section{Untuk grup $\left(\mathbf{Z}_{72},+\right)$}

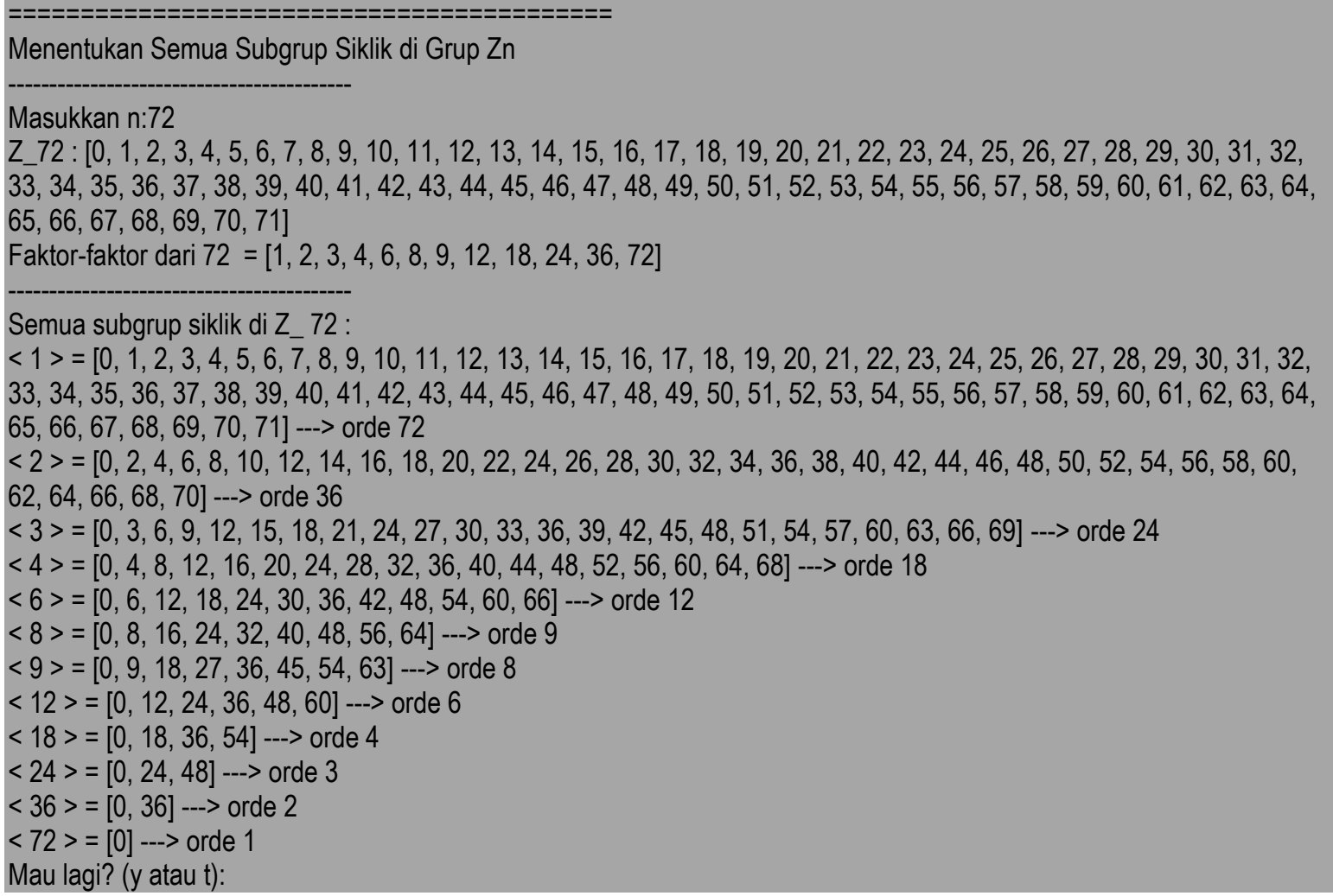

Dikirim: 13 Agustus 2018; Diterima: 17 September 2018; Dipublikasikan: 29 September 2018

Cara sitasi: Muktyas, I. B., dan Arifin, S. 2018. Semua Subgrup Siklik dari Grup $\left(\mathbf{Z}_{n},+\right)$. Jurnal Teorema: Teori dan Riset Matematika. Vol 3 No 2, Hal 177-186, September 2018. 


\section{Untuk grup $\left(\mathbf{Z}_{108},+\right)$}

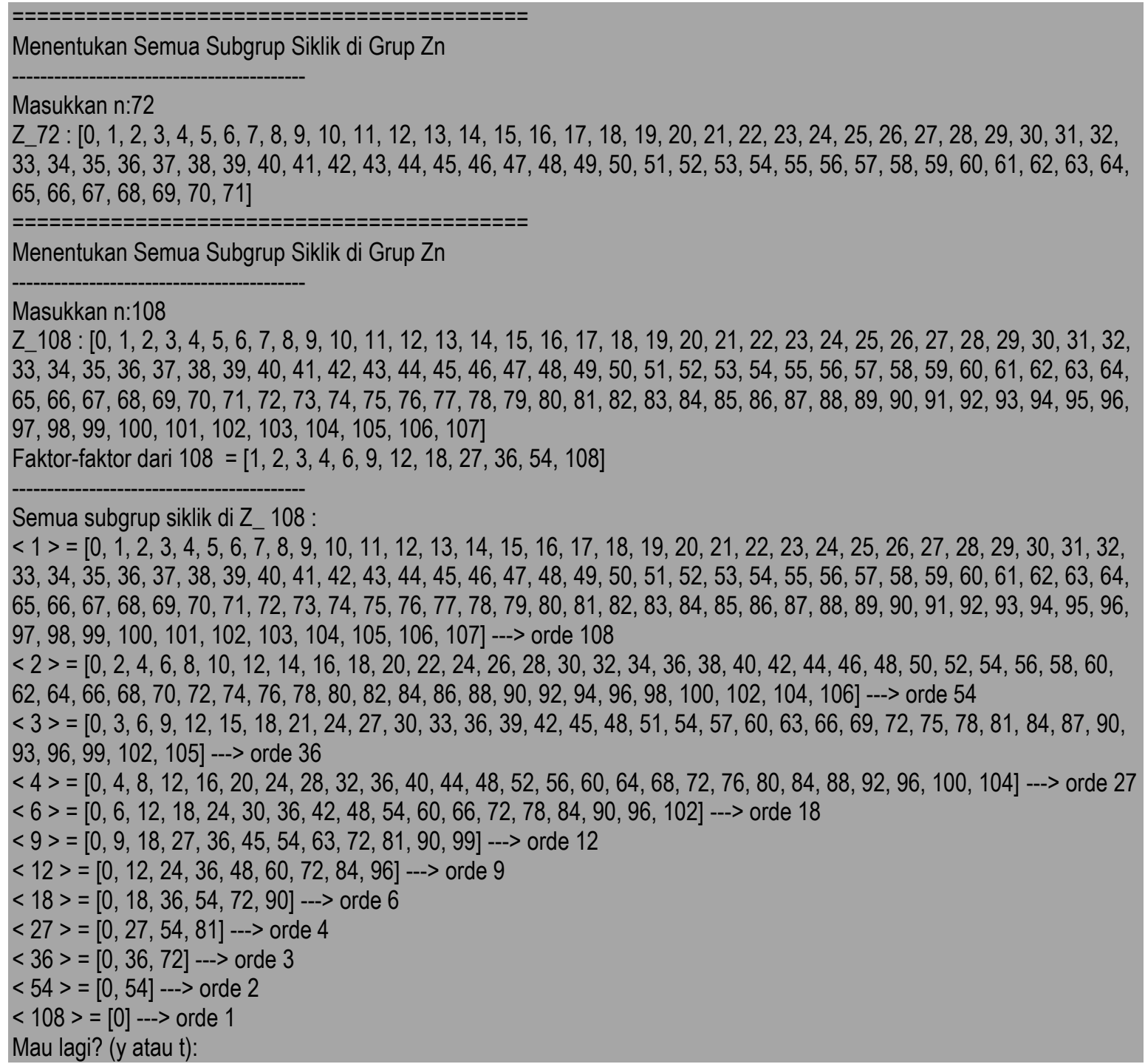

Dengan program yang telah dibuat, dapat dihitung nilai n maksimal sebesar $1.7 \times 10^{308}$. Nilai ini sesuai dengan batas atas bilangan bulat di Python yang dapat dicek dengan menuliskan perintah berikut ini. 


\section{KESIMPULAN}

Kesimpulan yang dapat diperoleh dari penelitian ini adalah sebagai berikut:

1. Semua subgrup dari suatu grup siklik juga merupakan grup siklik.

2. Semua subgrup siklik di grup $\left(\mathbf{Z}_{n},+\right)$ adalah subhimpunan yang dibangun oleh semua faktor dari $n$.

3. Dengan menggunakan program Python, dapat ditentukan semua subgrup siklik dari grup $\left(\mathbf{Z}_{n},+\right)$ dengan mudah.

\section{REKOMENDASI}

Rekomendasi yang dapat diberikan untuk penelitian selanjutnya adalah sebagai berikut:

1. Menentukan grup factor dari semua subgrup siklik untuk grup $\left(\mathbf{Z}_{n},+\right)$ dengan menggunakan Python.

2. Menentukan generator-generator dari semua subgrup siklik untuk grup $\left(\mathbf{Z}_{n},+\right)$ dengan menggunakan Python.

\section{UCAPAN TERIMA KASIH}

Penelitian ini terselenggara atas bantuan sarana dan prasarana dari STKIP Surya Tanggerang. Kami berterima kasih sedalam-dalamnya atas dukungannya selama ini.

\section{REFERENSI}

Dummit, D.S. (2004). Abstract Algebra, 3rd Edition. New York: John Wiley and Sons, Inc.

Fraleigh, J.B. (2000). A First Course in Abstract Algebra, $6^{\text {th }}$ Edition. New York: Addison-Wesley.

Gallian, J.A. (2017). Contemporary Abstract Algebra, 9th Edition. Boston: Cengage-Learning.

Herstein, I. (1996). Abstract Algebra, 3rd Edition. New York: Prentice Hall.

Isaacs, I.M. (1994). Algebra, A Graduate Course. New York: Wadsworth, Inc..

Malik, D.S. (1997). Fundamentals of Abstract Algebra. New York: The McGraw-Hill, Inc.

Python. (2018). [Online] Tersedia: https://www.python.org/ [30 April 2018]

QPython. (2018). [Online] Tersedia: //play.google.com/store/apps/details?id=org.qpython.qpy\&hl=en [30 April 2018]

Rotman, J.J. (2003). Advanced Modern Algebra. New York: Prentice Hall.

Dikirim: 13 Agustus 2018; Diterima: 17 September 2018; Dipublikasikan: 29 September 2018

Cara sitasi: Muktyas, I. B., dan Arifin, S. 2018. Semua Subgrup Siklik dari Grup $\left(\mathbf{Z}_{n},+\right)$. Jurnal Teorema: Teori dan Riset Matematika. Vol 3 No 2, Hal 177-186, September 2018. 
-186 Jurnal Teorema: Teori dan Riset Matematika Vol 3 No 2, Hal 186-186, September 2018

Dikirim: 13 Agustus 2018; Diterima: 17 September 2018; Dipublikasikan: 29 September 2018

Cara sitasi: Muktyas, I. B., dan Arifin, S. 2018. Semua Subgrup Siklik dari Grup $\left(\mathbf{Z}_{n},+\right)$. Jurnal Teorema: Teori dan Riset Matematika. Vol 3 No 2, Hal 177-186, September 2018. 